\title{
Estimating the age of power transformers using the concentration of furans in dielectric oil
}

\author{
F. Ortiz ${ }^{1}$, C. Fernández ${ }^{1}$, A. Santisteban ${ }^{1}$, F. Delgado ${ }^{1}$, and A. Ortiz ${ }^{1}$ \\ ${ }^{1}$ Department of Electrical Engineering \\ E.T.S.I.I., Cantabria University \\ 39005 Santander (Spain) \\ Phone/Fax number:+0034 942201374, e-mail: ortizfa@unican.es
}

\begin{abstract}
.
Transformers have an insulation system based on dielectric oil and paper. Several factors as shortcircuits, high load, or overheating influence the aging of the insulating system. Thus, these materials are decomposed during transformer operation, and its state determines the status of the transformer.

The degree of polymerization of dielectric paper is an indicator of its real condition. The concentration of furanic compounds in oil offer an estimation of paper degradation. Moreover, these compounds are easy to measure from oil samples.

This paper review equations which relate one or more properties of the insulating system with the life expectancy of the transformer. These equations were used in a fleet of transformers in order to estimate the accuracy of these mathematical models. Results show that these methods achieve the most reliable estimation when the transformers have operated less than 8 years. Nevertheless, when the transformers are older, the estimation of lifetime based on furanic compounds is quite erratic and should be improved.
\end{abstract}

\section{Key words}

Transformer, oil, paper, age, furans.

\section{Introduction}

Proper operation of a transformer is critical to ensuring transmission and distribution of electricity. Normal operation entails that the machine insulation system is gradually getting old. Most transformers have an insulation system based on dielectric oil and paper. The state of this insulation system finally determines the status of each unit. Several variables may influence the aging process in a transformer. Factors that influence the aging of the insulating system in these machines are: high currents, long periods of operation at high load, overheating, moisture, oxidation... Heat and the moisture of paper and oil are the most important causes in aging of the components of the dielectric system, while oxidation can greatly accelerate the degradation of dielectric paper.

Dielectric oil in transformers decomposes to hydrogen and low molecular weight gases such as methane, ethane, ethylene, acetylene... The percentage of each of these gases varies depending on the different conditions which may occur inside a transformer during its operation. On the other hand, when the solid insulation (usually Kraft paper) of these machines decomposes, products such as water, $\mathrm{CO}$ and $\mathrm{CO}_{2}$, as well as small amounts of furan compounds appear in oil. The concentration of $\mathrm{CO}$ and $\mathrm{CO}_{2}$ rises with increasing temperature, with accumulative oxygen present in the oil and with high moisture content in paper.

Thus, the knowledge of insulation decomposition allows the evaluation of its status through monitoring of various parameters. Factors like water content, acidity, dielectric strength, loss factor, gas content and concentration of furans in dielectric oil, are important indicators to determine the condition of a transformer. Additionally, transformer load, environmental conditions and the fault history should be considered in estimating the remaining life of a transformer.

This information allows to estimate the life of the machine and improve reliability. In addition, this monitoring helps to reduce operating costs, since the correct assessment of the state of transformer insulation systems predicts the risk and reliability of the operation and thus allows carrying out an effective economic management of maintenance strategies and replacement of transformers.

\section{Objective of this study}

In this paper the information gathered over the years in the control of oil quality of a population of seven industrial transformers has been analyzed, focusing on the concentration of furans (IEC 61198). Asset managers in utilities highly value the concentration of these compounds since it is related with the state of the dielectric paper, which is a key parameter for evaluation of the lifespan of a transformer. This way, the evolution of furans has been analyzed with the goal of performing an estimate of the age of these machines, trying to establish the accuracy that these measures can provide when it is necessary to determine the remaining life of transformers.

The fleet consists of transformers within a power range between 30 and 135MVA, the highest voltage of these machines being between 30 and $220 \mathrm{kV}$. The insulation 
system consists of Kraft paper and mineral oil in all the cases. The most common cooling systems amongst these transformers are ONAN, ONAF and OFWF. The manufacturers of these units are different and therefore so are their technologies. Two groups of age can be identified, the first corresponds to machines in operation since the $70 \mathrm{~s}$ of the last century, and the second corresponds to units manufactured in the first decade of the current century.

In the third section, this article describes different correlations between furan content in oil and the condition of dielectric paper, which have been proposed by several authors. The status of paper is measured by the degree of polymerization (DP). In the fourth section, the models described in the third part of the paper are used to estimate the age of the fleet of machines. Through equations which relate the DP with the temperature of power transformer operation and the time of operation. Finally, the conclusions extracted from this analysis are listed.

\section{Correlations between furans in oil and degree of polymerization of paper}

Furans are part of the products of cellulose degradation and are partially soluble in the insulating liquid. There are five types of furan compounds: 2-furaldehyde (2FAL), 5methyl-2-furaldehyde (5M2F), 5-hydroxymethyl-2furaldehyde $(5 \mathrm{H} 2 \mathrm{~F}), 2$-acetylfuran $(2 \mathrm{ACF})$ and 2-furfurol (2FOL). Among these compounds, 2-furaldehyde (2FAL) is the most representative. This is because this compound possess higher generation rate and stability inside a transformer [1].

Furans present in the oil are generated exclusively by the degradation of paper and pressboard. Thus, analyzing the concentration of furan, the aging of insulating paper can be assessed [1]. The formation of these compounds depends on the initial moisture in the paper, the temperature at which the paper is produced, the presence of oxygen and the type of paper used [2, 3].

The Table I shows different states of insulating paper based on the concentration of 2-FAL in the insulating oil [4].

Table I. Correlation between 2FAL concentration and the state of a transformer.

\begin{tabular}{|l|l|}
\hline Condition & Concentration $(\mathrm{ppm})$ \\
\hline Good & 2FAL $<0.5$ \\
\hline Acceptable & $0.5 \leq 2 \mathrm{FAL} \leq 1$ \\
\hline Need caution & $1.1 \leq 2 \mathrm{FAL} \leq 1.5$ \\
\hline Poor & $1.6 \leq 2 \mathrm{FAL} \leq 2$ \\
\hline Very poor & $2 \mathrm{FAL} \geq 2.1$ \\
\hline
\end{tabular}

Changes in furanic compounds profiles are produced by different causes as it was concluded by Myers et al. [5], Table II. These authors also pointed out that if in the insulating oil there are furan compounds apart from $2 \mathrm{FAL}$, may be an indicator that the insulating paper inside of a transformer suffers an unusual degradation.

Myers et al. [5] also concluded that thermally upgraded paper generate lower furanic compounds concentrations. Furanic compounds demonstrated lower stability in transformers whose insulation systems had been treated with dicyandiamide.

Table II. Causes of furanic compounds generation.

\begin{tabular}{|c|c|}
\hline Compound & Observed cause \\
\hline 2FAL & Overheating and normal aging \\
\hline $5 \mathrm{M} 2 \mathrm{~F}$ & High temperatures \\
\hline $2 \mathrm{ACF}$ & Rare, not defined causes \\
\hline $5 \mathrm{H} 2 \mathrm{~F}$ & Oxidation \\
\hline $2 \mathrm{FOL}$ & High moisture \\
\hline
\end{tabular}

The concentration of furan compounds (Cfur) in the oil is equally distributed in the transformer oil due to the molecular movement of oil according to Fick Law. This makes possible to be indifferent to sample transformer oil in one or another part of it, concentration of furanic compounds will be identical. This is very important because is more feasible to get oil samples than paper samples in real transformers. The oil sample can be obtained from the oil valve while collecting a paper sample requires to shut down the transformer [1].

Considering the concentration of furanic compounds in oil is a good indicator of the condition of the paper, favoured the establishment of correlations, Table III, which related furans concentration present in the mineral oil and the DP of the paper [6 - 14].

As it was indicated above, the DP is an indicator of the real aging of the dielectric paper, which determines the transformer's life. Therefore, it is possible to estimate the life of a transformer and compare it with the real life through the concentration of furanic compounds in transformer oil. This helps to have an assessment of the reliability of a transformer which is working.

\section{Estimation of transformer's life expectancy through mathematical models}

The present aged condition of a power transformer could be determined through mathematical expressions which establish a relation between the concentration of furans or DP and the age of the transformer. As it was explained before, the age of a transformer is defined by the aging of its insulation paper. If this paper suffers an unusual aging the life of a transformer will be shorter, for this reason is critical to estimate the rate of degradation of the paper. Collecting a paper sample requires to shut down the transformer, so it is not possible during transformer operation. Therefore other measure has to be used to estimate the degradation of dielectric paper, for instance the concentration of furanic compounds.

There are different authors [11, 15-18] who developed equations which relate one or more properties of the insulating system and the life expectancy of the transformer, Tables IV. This expectancy is based on the aging of the insulation paper.

In order to evaluate the suitability of some of these equations, it was estimated firstly the DP using the mathematical expressions proposed by [6-14]. Secondly, using the equations from $[11,15-18]$, the lifetime of the transformer based on paper aging was obtained. This methodology was applied to all the transformer that were 
studied in this work. The results of two of these

transformers are summarized in Tables V and VI.

Table IV. DP estimation through 2FAL concentration.

\begin{tabular}{|c|c|c|c|}
\hline Author & Equation DP = f([2FAL]) & {$[2-\mathrm{FAL}],\left[\mathrm{C}_{\text {fur }}\right]$} & Observations \\
\hline Vaurchex [6] & $D P=\frac{2.6-\log _{10}(2 F A L)}{0.0049}$ & ppm & \\
\hline Chendong [7] & $D P=\frac{1.51-\log _{10}(\text { Cfur })}{0.0035}$ & ppm & $150<\mathrm{DP}<1000$ \\
\hline Heisler y Banzer [8] & $D P=325 *\left(\frac{19}{13}-\log _{10}(2 F A L)\right)$ & ppm & $100<\mathrm{DP}<900$ \\
\hline De Pablo [9] & $D P=\frac{1850}{2 F A L+2.3}$ & ppm & $150<\mathrm{DP}<600$ \\
\hline De Pablo [10] & $D P=\frac{8.88 * D P_{0}}{8.88+2 F A L}$ & ppm & \\
\hline Dong et al. [11] & $D P=402.47-220.87 * \log _{10}\left(C_{\text {fur }}\right)$ & ppm & \\
\hline Li y Song. [12] & $D P=-121 * \ln \left(C_{\text {fur }}\right)+458$ & ppm & \\
\hline Chaohui et al. [13] & $D P=405.25-347.22 * \log _{10}(2 F A L)$ & ppm & \\
\hline Myers et al. I [14] & $D P=-285.7 * \log _{10}(2 F A L * 0.88)+1288.6$ & $\mathrm{ppb}$ & $\begin{array}{l}\text { Non-upgraded paper insulation } \\
\left(55^{\circ} \mathrm{C} \text { temperature rise }\right)\end{array}$ \\
\hline Myers et al. II [14] & $D P=-343.8 * \log _{10}\left(C_{f u r}\right)+1387.5$ & $\mathrm{ppb}$ & $\begin{array}{l}\text { Thermally upgraded paper } \\
\text { insulation }\left(55 / 65^{\circ} \mathrm{C} \text { temperature }\right. \\
\text { rise })\end{array}$ \\
\hline
\end{tabular}

Table VV. Mathematical models to estimate time of operation of a power transformer.

\begin{tabular}{|c|c|c|c|}
\hline Method & Author & Mathematical expression & Considerations \\
\hline 1 & Dong et al. [11] & $a=\frac{0.148+\log _{10}\left(C_{\text {fur }}\right)-0.01 * w}{0.02}$ & $\begin{array}{l}\mathrm{C}_{\text {fur }} \text { : average furfural concentration in } \\
\text { transformer oil }(\mathrm{mg} / \mathrm{l}) \\
\mathrm{w} \text { : water content } \\
\text { a: time of operation (year) }\end{array}$ \\
\hline 2 & Ekenstam [15] & $\begin{aligned} \frac{1}{D P_{t}} & -\frac{1}{D P_{0}}=k^{*} t \\
k & \rightarrow k_{10}\end{aligned}$ & $\begin{array}{l}\mathrm{DP}_{\mathrm{t}} \text { : degree of polimerization at time } \mathrm{t} \\
\mathrm{DP}_{0} \text { : initial degree of polimerization } \\
\mathrm{t} \text { : time of operation (hours) } \\
\mathrm{k} \text { : reaction rate constant }\end{array}$ \\
\hline 3 & Heywood et al. $[16,17]$ & $\frac{1}{D P_{t}}-\frac{1}{D P_{0}}=\frac{k_{10}}{k_{2}} *\left[1-e^{-k_{2} *_{t}}\right]$ & $\begin{array}{l}\mathrm{DP}_{\mathrm{t}}: \text { degree of polimerization at time } \mathrm{t} \\
\mathrm{DP}_{0} \text { : initial degree of polimerization } \\
\mathrm{t} \text { : time of operation (hours) } \\
\mathrm{k}_{10}: \text { initial rate } \\
\mathrm{k}_{2}: \text { rate at which } \mathrm{k}_{10} \text { changes }\end{array}$ \\
\hline 4 & Pradhan et al. [18] & Elapsed life $($ years $)=20.5 * \ln \left[\frac{1100}{D P}\right]$ & $\begin{array}{l}\text { Authors assume: } \mathrm{DP}_{0}=1100 \\
\text { Transformer life: } 35 \text { years }\end{array}$ \\
\hline
\end{tabular}

Table V. Life estimation using mathematical models for an old transformer (more than 30 years in operation).

\begin{tabular}{|c|c|c|c|c|c|c|}
\cline { 3 - 7 } \multicolumn{1}{c|}{} & \multirow{2}{*}{ Estimated DP } & \multicolumn{4}{c|}{ Paper age (years) } & $\begin{array}{c}\text { Transformer life } \\
\text { Time of operation } \\
\text { (years) }\end{array}$ \\
\cline { 3 - 7 } & & Dong [11] & Ekenstam [15] & Heywood [16, 17] & Pradhan [18] & 13 \\
\hline Vaurchex [6] & 594 & -13 & 29 & 30 & 18 & 36 \\
\hline Chendong [7] & 461 & -13 & 50 & 52 & 13 & 36 \\
\hline Heisler/Banzer [8] & 576 & -13 & 32 & 32 & 36 \\
\hline
\end{tabular}




\begin{tabular}{|c|c|c|c|c|c|c|} 
DePablo [9] & 663 & -13 & 22 & 22 & 10 & 36 \\
\hline De Pablo [10] & 948 & -13 & 2 & 2 & 3 & 36 \\
\hline Dong [11] & 425 & -13 & 58 & 61 & 19 & 36 \\
\hline Li/Song [12] & 487 & -13 & 45 & 47 & 17 & 36 \\
\hline Chaohui [13] & 514 & -13 & 41 & 42 & 16 & 36 \\
\hline Myers et al. I [14] & 536 & -13 & 37 & 38 & 15 & 36 \\
\hline Myers et al. II [14] & 391 & -13 & 67 & 70 & 21 & 36 \\
\hline
\end{tabular}

Table VII. Life estimation using mathematical models for a new transformer (less than 10 years in operation).

\begin{tabular}{|c|c|c|c|c|c|c|}
\hline & \multirow[b]{2}{*}{ Estimated DP } & \multicolumn{4}{|c|}{ Paper age (years) } & \multirow{2}{*}{$\begin{array}{l}\text { Transformer life } \\
\text { Time of operation } \\
\text { (years) }\end{array}$} \\
\hline & & Dong [11] & Ekenstam [15] & Heywood $[16,17]$ & Pradhan [18] & \\
\hline Vaurchex [6] & 841 & -77 & 8 & 8 & 5 & 8 \\
\hline Chendong [7] & 685 & -77 & 20 & 20 & 10 & 8 \\
\hline Heisler/Banzer [8] & 970 & -77 & 1 & 1 & 3 & 8 \\
\hline DePablo [9] & 794 & -77 & 11 & 11 & 7 & 8 \\
\hline De Pablo [10] & 997 & -77 & 0 & 0 & 2 & 8 \\
\hline Dong [11] & 598 & -77 & 29 & 29 & 12 & 8 \\
\hline Li/Song [12] & 705 & -77 & 18 & 18 & 9 & 8 \\
\hline Chaohui [13] & 935 & -77 & 3 & 3 & 3 & 8 \\
\hline Myers et al. I [14] & 882 & -77 & 6 & 6 & 5 & 8 \\
\hline Myers et al. II [14] & 661 & -77 & 22 & 22 & 10 & 8 \\
\hline
\end{tabular}

The estimation of lifetime obtained for all the transformers that have been studied in this work using the concentration of furanic compounds is not very accurate. It has been observed that the DP calculated through the concentration of furans is extremely high in old transformers (more than 30 years in operation). Most of the old transformers that were studied possess a DP around 600, which is not possible because the insulating paper has not been replaced since the transformer was manufactured. In the case of new transformers (less than 8 years in operation) the values of DP which were estimated are more logical. This might happen because furanic compunds have had less time to decompose or react with other substances which are inside the transformer oil.

The results have also showed that two of the methods used [15-17] obtain similar results when the DP is high. However, when these methods are applied to old transformers (more than 30 years) whose dielectric paper possess a DP around 200, their results are slightly different.

The application of the mathematical models have demonstrated that methods proposed by Vaurchex [6] and Myers et al. I [14] for non-upgraded paper achieve the most reliable results when the studied transformers have worked less than 8 years. Nevertheless, when the studied transformers are older, the estimation of lifetime based on furanic compounds is quite erratic. In this case, when the transformers are older (around 30 years) the models proposed by Dong et al. [11] and Li y Song. [12] obtain the results more similar to real data.

The use of several mathematical models for the estimation of lifetime of power transformers has shown that these methods are not suitable to predict the condition of a transformer accurately. It is needed to study the tendency of physicochemical and dielectric properties of insulating oil during the transformer's operation. The condition of a transformer cannot be determined considering only the most recent measures of oil's properties. This is because as the oil and paper age, the measured variables and the degradation products do not follow a continued tendency over time, fluctuations occur. Additionally, variables such as the working environment or load factor should be considered because these variables have influence on insulation aging.

Therefore, the measure of the transformers condition had to be based on various criteria related with factors which show the degradation of transformers due to insulating ageing. One method to carry out a comprehensive transformer condition assessment is the use of health index method. This method identifies if the power transformer is at or near the end of its operation life, types of possible faults and recommendations for future maintenance action.

\section{Conclusions}

The point in which a transformer must be replaced or its remaining lifespan, are very important issues for power system managers. These questions depend on the condition of the insulating system of these machines. In fact, it is essential to know the condition of the dielectric paper to carry out a proper management of transformer fleets.

So far, the tool more commonly used for estimation of transformers condition is the physicochemical analysis of oil, since it is easy to take an oil sample. On the contrary, it is not so easy to observe the status of dielectric paper. For this reason, it would be necessary to stop the unit and to extract the oil in order to have access to a sample of dielectric paper, which is not viable.

In many experimental laboratory works have been found a direct relationship between furan content and paper condition. However, analysing the data associated to the 
fleet of transformers studied in this article, large fluctuations of furan content has been observed over time. This makes almost impossible to find a correlation between furans and paper degradation when the transformer age is high. Only in the early operation of transformer would be possible to estimate approximately paper condition from furans content, considering the formulas proposed in the literature.

It is also necessary to take into account that substitution or regeneration of oil makes difficult to know the real condition of dielectric paper. The oil may have optimal physicochemical and dielectric properties even if the insulating paper is near the end of its useful life.

\section{Acknowledgement}

The research leading to these results has received funding from multiple sources during years but we would specifically like to acknowledge the support received in the later stages from the Spanish Plan Estatal de I+D under the grant agreement DPI2013-43897-P.

\section{References}

[1] R. Liao, C. Guo, K.Wang, L. Yang, S. Grzybowski and H. Sun, "Investigation on thermal aging characteristics of vegetable oil-paper Insulation with flowing dry air", IEEE Trans. Dielectr. Elect. Insul, (2013), Vol. 20(5), pp. 1649-1658.

[2] A. J. Kachler and I. Höhlein, "Aging of cellulose at transformer service temperatures. Part 1: Influence of type of oil and air on the degree of polymerization of pressboard, dissolved gases and furanic compounds in oil", IEEE Electr. Insul. Mag., (2005), Vol. 21(2), pp. 15-21.

[3] A. J. Kachler and I. Höhlein, "Aging of cellulose at transformer service temperatures. Part 2: Influence of moisture and temperature on degree of polymerization and formation of furanic compounds in free-breathing systems", IEEE Electr. Insul. Mag., (2005), Vol. 21(5), pp. 20-24.

[4] J. Haema and R. Phadungthin, "Development of condition evaluation for power transformer maintenance", in $4^{\text {th }}$ Int. Conf. on Power Eng. Energy and Elect. Drives, (2013), pp. 620-623.

[5] R. D. Stebbins, D. S. Myers and A. B. Shkolnik, "Furanic compounds in dielectric liquid samples: Review and update of diagnostic interpretation and estimation of insualtion ageing", in 7th Int. Conf. on Properties and Appl. of Dielectr. Mater., (2003), pp. 921-926.

[6] H. Lütke, I. Höhleim and A. J. Kachler, "Transformer aging research on furanic compounds dissolved in insulating oil", CIGRE (2002).

[7] X. Chendong, "Monitoring paper insulation ageing by measuring furfural contents in oil", in 7th Int. Symp. on High Voltage Eng., (1991), pp. 26-30.

[8] A. Heisler and A. Banzer, "Zustandsbeurteilung von transformatoren mit furfurol-bestimmung", Das Magazin für die Energiewirtschaft, (2003), pp. 58-59.

[9] A. De Pablo, "Interpretation of furanic compounds analysisdegradation models", CIGRE, (1997).

[10] A. De Pablo, "Furfural and ageing: How are they related", IEEE Colloquium on Insulating Liquids, (1999), pp. 5/1-5/4.

[11] M. Dong, Z. Yan, and G. J. Zhang, "Comprehensive diagnostic and aging assessment method of solid insulation in transformer", in Conf. on Electr. Insul. and Dielect. Phenomena. Annual Report, (2003) pp. 137-140.

[12] E. Li and B. Song, "Transformer Health Status Evaluation Model Based on Multi-feature Factors", in Int. Conf. on Power Syst. Technol., (2014), pp. 1417-1422.
[13] L. Chaohui, Z. Bide and Y. Yuchun, "The aging diagnosis of solid insulation for oil-immersed power transformers and its remaining life prediction", in Asia-Pacific Power and Energy Eng. Conf., (2010), pp. 1-3.

[14] A. B. Shkolnik, R. T. Rasor and S. D. Myers, "Statistical insights into furan interpretation using a large dielectric fluid testing database", in IEEE PES Transmission and Distribution Conf. and Expo., (2012), pp. 1-8.

[15] A. Ekenstam, "The behavior of cellulose in mineral acid solutions: kinetic study of the decomposition of cellulose in acid solutions", Ber. Deutschen Chem. Gesselschaft, (1936), Vol. 69(3), pp. 553-559.

[16] R. J. Heywood, G. C. Stevens, C. Fergunson and A. M. Emsley, "Life assessment of cable paper using slow thermal ramp methods", Thermochimica Acta, (1999), Vol. 232(2), pp. 189-195.

[17] R. J. Heywood, "The degradation models of cellulosic transformer insulation", Ph.D. dissertation, Dept. Chem, Surrey Univ., Guildford, Surrey, UK, (1997).

[18] M. K. Pradhan, T.S. Ramu, "On the estimation of elapsed life of oil-immersed power transformers", IEEE Trans. Power Del., (2005), Vol. 20(3), pp. 1962-1969. 